\title{
A CALIBRATION METHOD OF THE LASER TRIANGULAR MEASURING SYSTEM TO EVALUATE WOOD SURFACE ROUGHNESS
}

\author{
Endre Magoss, Sándor Tatai, Zsolt Molnár \\ UNIVERSITY OF SOPRON \\ HUNGARY \\ INGRID FUCHS \\ Institut Für Holztechnologie Dresden \\ GemeinnütZige GmbH \\ Germany \\ (Received July 20I9)
}

\begin{abstract}
Due to the fact that wood roughness measurement results measured with stylus and optical methods are not always comparable a new calibration method was proposed. In order to compare the surface roughness parameters of the stylus tactile $2 \mathrm{D}$ roughness parameters and the optical $3 \mathrm{D}$ roughness parameters a systematic experiment has been carried out on fourteen wood species. The essence of this calibration method is the use of metal calibration etalons for $R_{z}=20 \mu \mathrm{m}$ and $R_{z}=30 \mu \mathrm{m}$ and the filter option of the optical measuring apparatus. After the calibration process, the roughness profiles taken with the optical and stylus units were much closer each to other decreasing the difference in the measurement results of the two systems. Our study prove that the laser triangular method is less usable for the planed wood surfaces.
\end{abstract}

KEYWORDS: Surface roughness, calibration, 2D and 3D roughness parameters, roughness measurement.

\section{INTRODUCTION}

For wood and wood product have not developed yet a universal measuring method for evaluating of the surface roughness (Gurau and Irle 2017). The visual examination of the wood surfaces are limited and generally rely on the subjective human perception (Sandak and Tanaka 2002, Sinn et al. 2008). Different methods have been used to get accurate surface roughness parameters. Neither the light sectioning (Peters and Cumming 1970, Yang et al. 2006) nor the image analysis (Faust 1987) are not applicable to evaluate wood surface roughness in every case. 
The laser non-contact techniques are already applied for wood surfaces (Funck et al. 1992, Sachsse 1994, Lundberg and Porankiewicz 1995, Larricq et al. 2000, Goli and Sandak 2016) but, due to the porosity and reflectance of the wood material surface, laser techniques cannot always accurately characterize the surface roughness. Westkämper and Schadoffsky (1995) compared the laser focus and the stylus methods and found that the stylus was better able to detect wood surface roughness especially regarding on big porous species. The stylus method is more accurate to evaluate wood surface roughness than the laser triangulation device (Gurau et al. 2001). The laser and the stylus method registers different surface roughness profile from the same measuring line. A further problem that the 3D surface roughness parameter maximum height $S_{z}$, due to its definition, is determined by extreme values and it is much higher than its $2 \mathrm{D}$ counterpart maximum height of profile $R_{z}$. Therefore, $S_{z}$ and $R_{z}$ are hardly comparable at all. A further observation that the $3 \mathrm{D}$ core height $\mathrm{Sk}$ value is systematically higher than the corresponding 2D Core roughness depth $R_{k}$ value for the same surface. Consequently, to compare the applicability of the $2 \mathrm{D}$ stylus tracing system and the 3D laser measuring method for measuring wood surface roughness is an important task. The $2 \mathrm{D}$ model distinguishes the waviness from roughness by using electric filters. Two main filters have been standardised, 2RC and the digital phase-correction filter (GS). The 3D model shows the same problem of the need to distinguish waviness from roughness as the $2 \mathrm{D}$ model does. Therefore, it is possible to solve the problems of distinguishing waviness from roughness by using the existing possibilities. As a result, it is suggested that the distinguishing of roughness from waviness may be solved by dividing the surface into segments and connecting them by a polynomial into a unique surface, which presents waviness (Indof and Mahovic 2000). It is a proven fact that a single roughness parameter does not provide a comprehensive description for three-dimensional analysis of processed surfaces, even in the case of homogeneous metal surfaces (Dong et al. 1994). Wood is anisotropic porous material therefore to evaluate the wood surface roughness is difficult measuring task (Thoma et al. 2015, Laina et al. 2017, Magoss 2017). By investigating square areas on finished steel rings and polymeric blocks is observed that the sum $\left(R_{p k}+R_{k}+R_{v k}\right)$ and $\left(S_{p k}+S_{k}+S_{v k}\right)$, respectively, is more adequate for pointing out the material distribution within the surface topography. The study stated that the 3D measurements on both non-worn and worn surfaces have characterized the quality of the investigated steel and polymeric surfaces in a good manner (Deleanu et al. 2012). To characterize the internal relationships between roughness parameters of wood the summarized Abbott parameters $(\mathrm{Rpk}+\mathrm{Rk}+\mathrm{Rvk})$ and $(\mathrm{Spk}+\mathrm{Sk}+\mathrm{Svk})$ are also applicable (Csanády and Magoss 2012, Csanády et al. 2015). Singh and Vatsalya recommended the use of autocorrelation function to investigate surface roughness. This approach is based on the idea that profile readings can be treated as random signals. This type of analysis has found extensive use in random signal processing in communication (Singh and Vatsalya 2015).

Investigating wood surfaces, both the contact styles and laser techniques are used today to provide data points. However, stylus tracing remains the most accurate measuring technique despite its limitations and slow processing speed, compared to the laser technique, which is only usable in off-line measurements (Sandak and Tanaka 2002).

\section{MATERIALS AND METHODS}

In order to define the correlation between the stylus tactile $2 \mathrm{D}$ roughness parameters and the optical 3D roughness parameters systematic experiment series has been carried out. Investigations have been performed on fourteen wood species: 
- spruce (Picea abies Karst.)

- larch (Larix decidua Mill.)

- Scots pine (Pinus sylvestris L.)

- sessile oak (Quercus petraea Liebl.)

- Black locust (Robinia pseudoacacia L.)

- beech (Fagus sylvatica L.)

- aspen (Populus tremula L.)

- Carpathian walnut (Juglans regia L.)

- field maple (Acer campestre L.)

- Thailand rosewood (Dalbergia cochinchinensis P.)

- West Indian locust (Hymenaea courbaril L.)

- balsa (Ochroma lagopus SW.)

- red ironwood (Lophira alata Banks.)

- wenge (Millettia laurentii De Wild.)

From each wood species, 10 samples have been taken and both wood processing methods (planing and sanding) were represented by 5 samples. The samples were prepared with dimensions of $100 \times 100 \times 25$ mm (long x rad x tang). For investigations all defect free, homogenous, radially cut boards have been selected (Fig. 1). Before surface preparation the wood material has been kept for 2 months in climate chamber at $23^{\circ} \mathrm{C}$ and $50 \%$ relative humidity. When adjusting the different machining parameters, the target was to achieve the smoothest surface possible, so the machining conditions have been set after several preliminary trials. After two months the samples moisture content was between $8 \%-12 \%$. Under the measuring process, the climatic circumstances did not change.

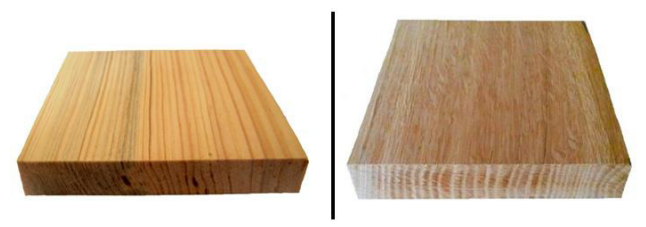

Fig. 1: Scotch pine and sessile oak samples.

Machine parameters are chosen which produced the smoothest surface. The sanding was completed with a KÜNDIG Brilliant 2/1350 -CEd-L wide-belt sanding machine using IHD (Institut für Holztechnologie Dresden) sanding instructions (IHD 2012), and Tab. 1 displays the sanding parameters. Planing has been performed with PANHANS 436 type planer. The cutter head of planer had four knives with rake angle of $20^{\circ}$ and knife angle of $50^{\circ}$. The rotation speed was $5000 \mathrm{~min}^{-1}$ and the feed speed was $3 \mathrm{~m} \cdot \mathrm{min}^{-1}$.

The 3D optical measurement was performed by a GF Messtechnik Micro CAD type 3D laser triangular surface roughness-measuring instrument. Measurements were based on phase measuring fringe projection (GF Messtechnik 2008). For measuring, the 2D surface roughness parameters Mahr PRK Perthometer was used. In order to have comparability, the measuring length was $12.5 \mathrm{~mm}$; the resolution was in both cases $8 \mu \mathrm{m}$. The stylus with $90^{\circ}$ tip angle and a spherical tip of $5 \mu \mathrm{m}$ radius was applied. The primary $\mathrm{P}$ profile was measured and processed to avoid the influence of the filtering process. 
Tab. 1: Sanding parameters.

\begin{tabular}{|c|c|c|c|c|c|}
\hline \multicolumn{2}{|c|}{ Wood } & $\begin{array}{c}\text { Cut thickness } \\
(\mathrm{mm})\end{array}$ & $\begin{array}{c}\text { Feed rate } \\
\left(\mathrm{m} \cdot \mathrm{min}^{-1}\right)\end{array}$ & $\begin{array}{c}\text { Belt speed } \\
\left(\mathrm{m} \cdot \mathrm{s}^{-1}\right)\end{array}$ & Grit size \\
\hline \multirow{2}{*}{ Hardwood } & 1.step & 0.2 & 7 & 10 & P100 \\
\cline { 2 - 6 } & 2. step & 0.1 & 7 & 8 & P1800 \\
\hline \multirow{2}{*}{ Softwood } & 1. step & 0.2 & 8 & 11 & P100 \\
\cline { 2 - 6 } & 2. step & 0.1 & 8 & 9 & P1800 \\
\hline
\end{tabular}

In the first step $12.5 \mathrm{~mm} \times 9.5 \mathrm{~mm}$ surface area was registered by the optical system then the same spot is measured by the perthometer. In the frame of the $2 \mathrm{D}$ tactile measurement of 50 profiles were recorded. The interval between the profiles was $0.2 \mathrm{~mm}$ (Fig. 2). The 50 evaluated profiles are averaged and their standard deviation determined. The first profile served as a standard 2D measurement result.

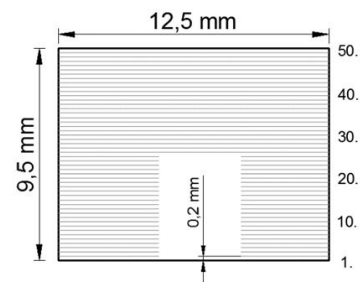

Fig. 2: The setup of the stylus measuring method.

The positioning of the samples was important part of the research, both measuring systems must record the same surface area. In order to achieve accurate positioning, marking was used (Fig. 3) and the positioning was made by the $\mathrm{XY}$ axis cross guide micrometre of the manual sliding tables.
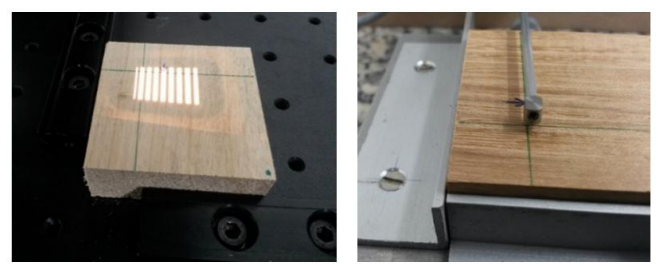

Fig. 3: Positioning of the samples.

\section{RESULTS AND DISCUSSION}

Data evaluation based on 3D surface topography measurements has been made using ODSCAD 6.0 software. The 2D profile was also generated from the 3D surface area therefore, the surface roughness profiles of the two measuring methods come to comparable. Due to the accurate positioning, in Fig. 4 the comparison the surface roughness profiles are fully possible. The waviness of the profiles is almost the same, but the profiles of the optical system contain bigger irregularities. Consequently, the optical system registered higher surface roughness parameters. It should be noted that Dalbergia samples had a density of $1180 \mathrm{~kg} \cdot \mathrm{m}^{-3}$ with more specular reflection compared to the other two species. 

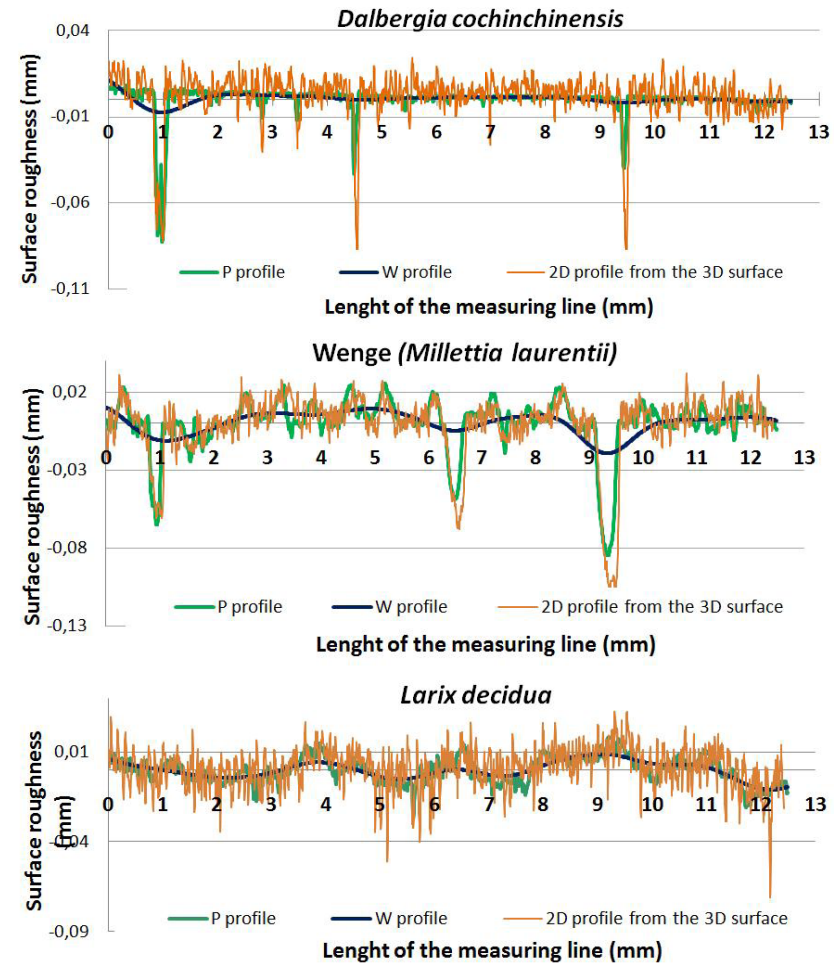

Fig. 4: Comparison of the optical and the stylus type measured profiles of three wood species.

The surface roughness parameters geometric mean height $S_{a}$ and geometric mean height of profile $P_{a}$ are summarized on the Fig. 5. The 2D profile roughness parameters $P$ (EN ISO 4287: 2000 ) of both measuring methods and the optical 3D surface roughness parameters $S$ (EN ISO 25178-2: 2012) also recorded. The $2 \mathrm{D}$ profile roughness parameters related to the surface are the average value of the 50 profile values and the standard deviation of the 50 values are also depicted.

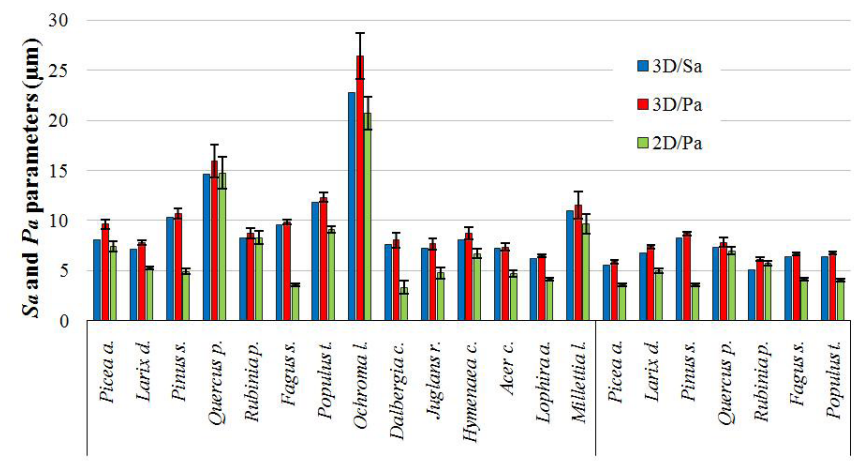

Fig. 5: 2-D surface roughness parameters $P$ (EN ISO 4287: 2000) of both measuring methods and the optical 3-D surface roughness parameters S (EN ISO 25178-2: 2012). 
The most reliable roughness parameter is the sum of Abbott parameters $\left(S_{p k}+S_{k}+S_{v k}\right)$ and its counterpart $\left(P_{p k}+P_{k}+P_{v k}\right)$. The maximum height profile from peak height to valley depth is well defined and its measured value, using different measuring system, must be in good correlation.

The evaluation of Abbott curve parameters are also showed considerable deviance, especially by the summarized Abbott parameters $\left(P_{p k}+P_{k}+P_{v k}\right)$ and $\left(S_{p k}+S_{k}+S_{v k}\right)$ (Fig. 6). The samples with high density have shown the biggest difference. For example the Thailand rosewood (Dalbergia cochinchinensis) samples provided almost three times higher Abbott parameters by the optical measuring method than the stylus type system. The reason behind this phenomenon is likely the light reflection properties of these wood species.

The optical measuring system may be sensitive to the reflection properties of the surface: in case of diffuse reflection the measuring signal is always coming back to the receiving unit. At the same time, in the case of specular reflection, the measuring signal may arrive the receiving unit either partly or not at all. High density hardwood species are inclined to show specular reflection but the machining process has also definite influence on the reflection properties (Csanády et al. 2015). The highest deviation in Fig. 6 are produced by planed surfaces.

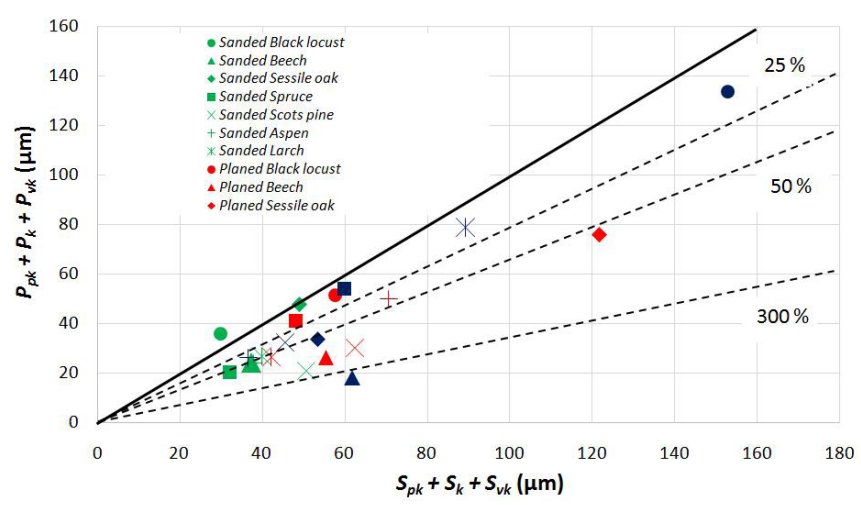

Fig. 6: Comparison of the summarized Abbott parameters $\left(P_{p k}+P_{k}+P_{v k}\right)$ and $\left(S_{p k}+S_{k}+S_{v k}\right)$.

The wood material is an inhomogeneous material and, therefore, we tried to eliminate the biasing factors of the wood surface. For this purpose the metal master pieces of the perthometer was applied (Fig. 7). The resulted surface roughness profiles (Fig. 8) and parameters of the two measuring systems are showed the same tendency similar to the profiles and parameters which are derived from the wood samples. Consequently the difference of the surface roughness parameters is caused by the different working method of the laser triangular and the stylus type measuring systems. It means that the surface roughness parameters of the two systems are directly not comparable. To the proper use of the laser triangular surface roughness measuring method it is recommended the use of the tactile method to calibrate the optical measuring system.
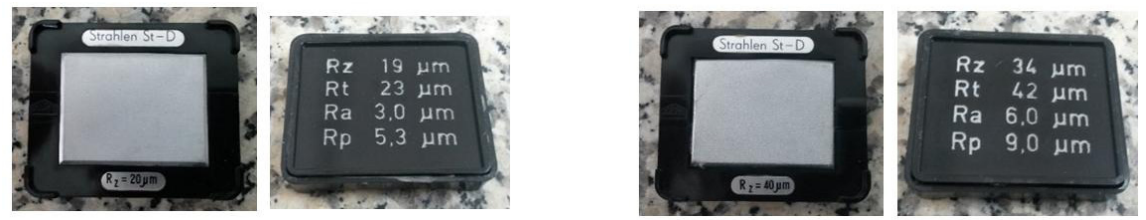

Fig. 7: Metal master pieces of the perthometer. 


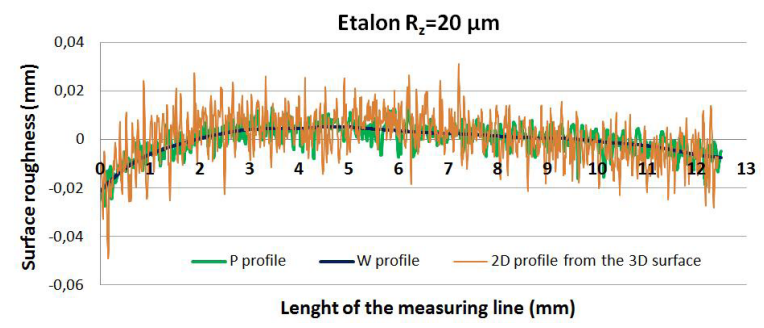

Fig. 8: Comparison of the optical and the stylus type measured profiles of the master piece.

The filter options of the laser triangular measuring apparatus could be the proper tool to calibrate the surface roughness profiles. The filter process was exerted to get closer the surface roughness profile of the optical method to the profiles of the tactile measuring system. After the calibration process the profiles of the two systems are almost the same (Fig. 9).

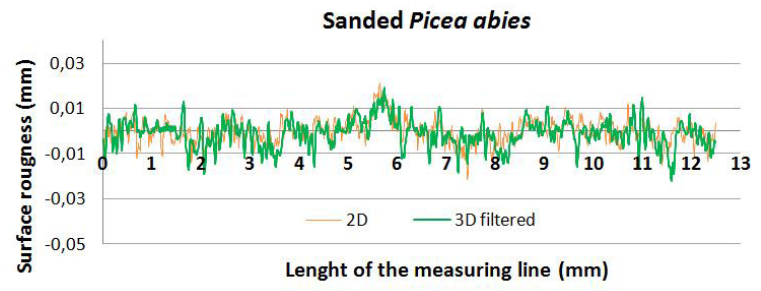

Fig. 9: Comparison of the optical and the stylus type measured profiles of the spruce sample after calibration.

Fig. 10 generally shows a good agreement between optical and stylus methods but in some cases the difference could not be fully eliminated. First of all the dense hardwood species show more deviation. Note that the Scotch pine used has higher density around $700 \mathrm{~kg} \cdot \mathrm{m}^{-3}$ and a prominent colour difference between early and late wood which may also have some disturbing effect in the optical system.

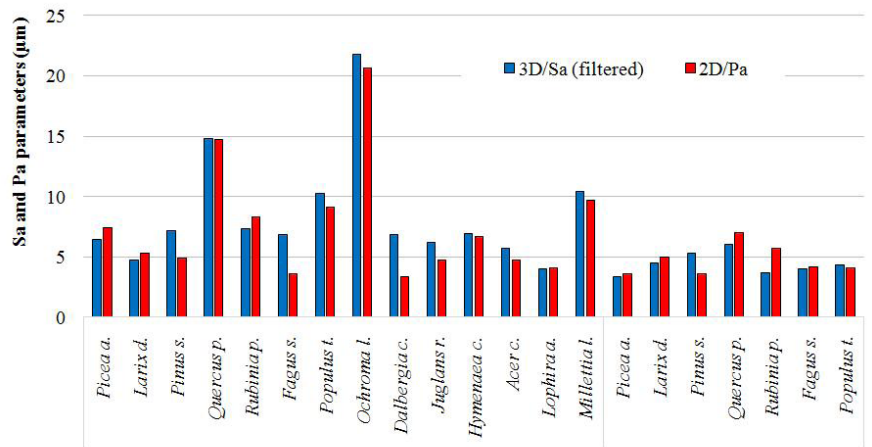

Fig. 10: 2-D surface roughness parameters $P$ (EN ISO 4287: 2000) of both measuring methods and the optical 3-D surface roughness parameters S (EN ISO 25178-2: 2012) after the calibration. 
Finally, a question may be the reflection properties of the metal master piece (etalon) which is not known. In principle, several etalons should have been used which would differently reflect similarly to the measured wood species. Nevertheless, the proposed calibration procedure may decrease the deviations between the optical and stylus measuring systems due to their different operation principles.

\section{CONCLUSIONS}

The advantages of the optical surface roughness measuring system are the processing speed and the non-contact working method. To exploit these features the laser triangular measuring system calibration is needed. This process could base on the results of the stylus type measuring system. The tactile measuring method has its own disadvantages but for wood material is widely used. Gurau and Irle (2017) have given specific recommendations regarding the selection of the measuring instrument (stylus), the length of evaluation (at least $40 \mathrm{~mm}$ ), the measuring resolution $(5 \mu \mathrm{m})$, removal of form error (with or without prior removal of wood pores), the use of the robust Gaussian regression filter, appropriate cut-off length $(2.5 \mathrm{~mm})$. After the calibration, the 2D surface roughness parameters P (EN ISO 4287: 2000) of both measuring methods and the optical 3D surface roughness parameters S (EN ISO 25178-2: 2012) are became to be comparable. The laser triangular method is less usable for the planed wood surfaces, especially by wood species with high density. The next step of this research work will be the investigation the applicability of the confocal microscopy for evaluating wood surface roughness.

\section{ACKNOWLEDGEMENTS}

The research described in this article/study was carried out as part of the project GINOP2.3.3-15-2016-00038, "Further processing of wood and wood products based on green chemistry and technology, through creating modern research infrastructure" in the framework of the Széchenyi 2020 Programme. The implementation of this project is supported by the European Union, co-financed by the European Regional Development Fund.

\section{REFERENCES}

1. Deleanu, L., Georgescu, C., Suciu, C., 2012: A comparison between 2D and 3D surface parameters for evaluating the quality of surfaces. In: Proceedings of the $3^{\text {rd }}$ International Conference on diagnosis and prediction in mechanical engineering systems. May 31 - June 1, Galati, Romania, Pp 1-9.

2. Dong, W.P., Sullivan, P.J., Stout, K.J., 1994: Comprehensive study of parameters for characterizing three-dimensional surface topography: III. Parameters for characterizing amplitude and some functional properties. Wear 178(1-2): 29-43.

3. Csanády, E., Magoss, E., 2013: Mechanics of wood machining. Springer Verlag, Berlin 199 pp.

4. Csanády, E., Magoss, E., Tolvaj, L., 2015: Quality of machined wood surfaces. Springer Verlag, Berlin, 257 pp.

5. EN ISO 4287, 2000: Geometrical product specification (GPS). Surface texture. Profile method. Terms, definitions and surface texture parameters. 
6. EN ISO 25178-2, 2012: Geometrical product specifications (GPS). Surface texture: Areal. Part 2: Terms, definitions and surface texture parameters.

7. Faust, T.D., 1987: Real time measurement of veneer surface roughness by image analysis. Forest Product Journal 37(6): 34-40.

8. Funck, J.W., Forrer, J.B., Butler, D.A., Brunner, C.C., Maristany, A.G., 1992: Measuring surface roughness on wood: a comparison of laser scatter and stylus tracing approaches. SPIE 1821: 173-184.

9. Goli, G., Sandak, J., 2016: Proposal of a new method for the rapid assessment of wood machinability and cutting tool performance in peripheral milling. European Journal of Wood and Wood Products 74(6): 867-874.

10. Gurau, L., Irle, M., 2017: Surface roughness evaluation methods for wood products: Review. Current Forestry Report 3: 119-131.

11. Gurau, L., Mansfield-Williams, H., Irle, M., 2001: A comparison of laser triangulation and stylus scanning for measuring the roughness of sanded wood surfaces. In: Bučar, B. (ed.) Proceedings of the 5th International conference on the development of wood science, wood technology and forestry. Ljubliana, Slovenia, 5-7 September 2001, Pp 299-310.

12. Indof, D., Mahovic, S., 2000: 2D and 3D approach to measuring roughness parameters. Proceedings of 16th International measurement confederation, Vienna, Pp 121-126.

13. Laina, R., Sanz-Lobera, A., Villasante, A., López-Espí, P., Martínez-Rojas, J.A., Alpuente, J., Sánchez-Montero, R., Vignote, S., 2017: Effect of the anatomical structure, wood properties and machining conditions on surface roughness of wood. Maderas. Ciencia y Tecnología 19(2): 203-212.

14. Larricq, P., Costes, J.P., Le Breton, P., Cassou, G., 2000: Quality surface characteristics in high speed machining. Proceedings of the International symposium on wood machining, Vienna, Pp 203-209.

15. Lundberg, IAS., Porankiewicz, B., 1995: Studies of non contact methods for roughness measurements on wood surfaces. Holz als Roh- und Werkstoff 53: 309-314.

16. Magoss, E., 2017. Evaluating of surface roughness of sanded wood. Wood Research 60(5): 783-790.

17. Magoss, E., Molnár, Zs., Suri, V., Fuchs, I., 2019: Evaluating of wetting-induced effects on the surface stability of sanded wood. Wood Research 64(3): 401-410.

18. Sachsse, H., 1994: Die Beurteilung von Holzoberflächen (Evaluation of wood surface roughness). Holz-Zentralblatt Kolloquium Tharand 69(11): 38-39.

19. Sandak, J., Tanaka, C., Ohtani, T., 2004: Evaluation of surface smoothness by a laser displacement sensor II: comparison of lateral effect photodiode and multielement array. Journal of Wood Science 50(1): 22-27

20. Sandak, J., Tanaka, C., 2002: Evaluation of surface smoothness by laser displacement sensor. In: Proceedings on the 3rd International science conference. Zvolen, Slovakia, 17-19 October, Pp 112-118.

21. Singh, R., Vatsalya, R., 2015: Evolution of 3D surface parameters: A comprehensive survey. The International Journal of Engineering and Science 4(2): 04-10.

22. Sinn, G., Sandak, J., Ramananantoandro, T., 2009: Properties of wood surfaces characterization and measurement. A review COST Action E35 2004-2008. Wood machining-micromechanics and fracture. Holzforschung 63(2): 196-203.

23. Peters, C.C., Cumming, J.D., 1970: Measuring wood. Surface smoothness: A review. Forest Products Journal 20(12): 40-43. 
24. Thoma, H., Peri, L., Lato, E., 2015: Evaluation of wood surface roughness depending on species characteristics. Maderas Ciencia y tecnología 17(2): 285-292.

25. Yang, D., Jackson, M., Parkin, R.M., 2006: Inspection of wood surface waviness defects using the light sectioning method. Proceedings of the Institution of Mechanical Engineers. Part I. Journal of Systems and Control Engineering 220(7): 617-626.

26. Westkämper, E., Schadoffsky, O., 1995: Oberflächentopographie von Massivholz Einflüsse bei der messtechnischen Erfassung und Bewertung (Teil 1). (Surface topography of wood. Part 1.). HOB Die Holzbearbeitung 42(3): 74-78.

27. Westkämper, E., Schadoffsky, O., 1995: Oberflächentopographie von Massivholz Einflüsse bei der messtechnischen Erfassung und Bewertung (Teil 2) (Surface topography of wood. Part 2.). HOB Die Holzbearbeitung 42(4): 50-54.

Endre Magoss*, SÁndor Tatai, Zsolt Molnár

UNIVERSITY OF SOPRON

Simonyi Károly Faculty of Engineering Wood Sciences and Applied Arts

BajCsY-Zs. U. 4.

9400 Sopron

HungARY

*Corresponding author: magoss.endre@uni-sopron.hu

\author{
INGRID FUCHS \\ Institut Für Holztechnologie Dresden \\ Gemeinnützige Gmbi \\ Zellescher Weg 24 \\ oi 217 Dresden \\ Germany
}

